\title{
International Journal of General Medicine \& Surgery
}

\section{Prevalence of Drug-Drug Interactions in Intensive Care Unit of a Multispecialty Hospital} at Hyderabad, South India

\author{
Mohsina Hassan*, Akbar FM, Rafia Begum, Humera Begum and Talat Z \\ Department of Pharmacy Practice, Nizam Institute of Pharmacy, Jawaharlal Nehru Technological University Hyderabad, India
}

Article info

Received 11 October 2019

Revised 29 November 2019

Published 05 December 2019

*Corresponding author: Hassan

M, Department of Pharmacy

Practice, Nizam Institute of

Pharmacy, Hyderabad, India;

E-mail:drmh09@gmail.com

\begin{abstract}
Background: A drug interaction occurs when the effect of a drug is altered by other drugs; it may affect the drug's pharmacokinetics or pharmacodynamics. In pharmacokinetic type of drug interactions, a drug alters the absorption of another drug or the, distribution, metabolism, or elimination of another drug; in pharmacodynamics type of interactions, the action of a drug is altered by other drugs. This study was conducted to investigate the prevalence of potential drug-drug interaction, to examine the number of drugs used and prevalence of polypharmacy, to determine the frequency, severity and the drug combinations involved in DDIs occurring in ICU.
\end{abstract}

Materials and Methods: This is an observational study carried out at an ICU of a multi-specialty hospital. Patient of age group between 18-80 years of both the gender admitted for more than 24 hours and prescribed at least more than 2 drugs are included in the study. All the relevant and necessary details of the patients including the demographic data, laboratory parameters and drug therapy details were collected from the patient case notes. The patient drug therapy were reviewed every day and assessed for any drug-drug interactions.

Results: A total of 151 prescriptions were assessed out of which 82 were male and 69 were female. In the study group the average age was 54.6 and association was found between the DI and increased age. There were around 1,709 drugs prescribed and average drugs per prescription was 11.2. From a total of 276 drug interactions found, 46 drug interactions were of major severity, 184 drug interactions of moderate severity and 46 drug interactions of minor severity. Mechanism of DDI was identified of which 85(30.7\%) DDI showed pharmacokinetic mechanism, 135(48.9\%) DDI showed pharmacodynamic mechanism and 57(20.6\%) DDI showed unknown mechanism. The prevalence of drug-drug interaction was seen more in age group of 41-60 years.

Conclusion: Prevalence of potential DDIs is high in intensive care units and is predisposed by factors such as a number of drugs received by patients, comorbid conditions; complex pharmacotherapies administered and geriatrics. Health professionals who provide care to these patients should be aware to identify and prevent possible drug events. Also, the pharmacist's involvement might have allowed greater familiarity of physicians regarding clinically relevant drug-drug interactions, optimizing the quality of the prescriptions, especially in critical care units. Therefore, 
the outcome of clinical pharmacist's applications and intervenes may promote well-being, preventing and monitoring adverse events, intervening and contributing to pharmacotherapy effectiveness and prioritizing patient safety.

Keywords: Polypharmacy, pharmacist management, clinical pharmacist, pharmacotherapy effectiveness, drug interactions, ICU.

\section{Introduction}

The term drug-drug interactions refers to the influence of one drug upon another, e.g., where a second drug stimulates catabolism of the first drug, thereby reducing efficacy of the first drug, or where a second drug inhibits catabolism of the first drug, thereby increasing its efficacy (or increasing its toxicity). A drug interaction occurs when the effect of a drug is altered by other drugs; it may affect the drug's pharmacokinetics or pharmacodynamics. In pharmacodynamics type of interactions, the action of a drug is altered by other drugs, whereas in Pharmacokinetic type of interactions, a drug alters the ADME of another drug [1].

An Intensive Care Unit (ICU) is a special facility within a hospital that is dedicated to treating patients who are critically ill. Intensive Care Units are complex setups involving close monitoring of patients of critical condition. Patients of ICU are also predisposed to have PDDI's because of their comorbidities, long list of drugs administered. Better outcomes in ICUs can only be achieved with better patient understanding, better drug regimens, and better knowledge of drug-drug interactions that are involved commonly in an ICU setup. Therefore, it is necessary to avoid possible drugdrug interactions, by the inputs of a clinical pharmacist, vigilance of symptoms by nurses, and dedication of all health care professionals [2]. Critically ill patients are particularly prone to drug interactions, as they have several related risk factors such as higher age, multidrug therapy, and long period of hospital stay. Due to the complexity of therapy needed for the treatment of a disease, its primary factors, its complications and accompanying comorbidities such as, diabetes and hypertension, malignancy and pulmonary disorders, the prescribed drugs increase which translate to a major risk factor for pDDIs. Apart from diseases, there are changes in renal and hepatic function with increasing age, malnutrition and reduced homeostatic mechanisms makes the aging patients more sensitive to the additive effects of 2 or more drugs making them more disposed to serious drug-drug interactions. Therefore, the objectives of treatment are vital while assessing the clinical effect of a drug interaction as equilibrium needs to be struck between increased drug toxicity and reduced therapeutic effect [3]. Positive association between polypharmacy and drug-drug interactions has been demonstrated in various studies. The risk of drug-drug interactions can increase from approx. $6 \%$ in patients taking only two drugs to $50 \%$ in those taking five drugs and $100 \%$ in those patients taking ten drugs [4]. With an increase in the number of patients, numerous diseases, and complex therapeutic regimens, polypharmacy has become unavoidable in ICU. Polypharmacy increases the risks of drug AEs, especially the DDIs, and that leads to elevated healthcare costs, morbidity and mortality [5]. Potential drug-drug interaction is when a drug action is likely to be altered by the concomitant administration of another drug. In general, critically ill patients are under high usage of antibiotics; which is challenging to use them carefully with a control on ADRs and DIs. The average number of therapeutic interventions is also usually high in Intensive care units. Drug interactions are therefore one of the highest occurring drug-related problems in the ICU [6].

Risks: The use of many medications at a time can lead to mistakes in adhering or taking them incorrectly. Healthcare professionals might be unaware of what drugs their patients are taking, leading to prescribing errors. For example, a same type of drug could be prescribed twice by different clinicians. A prescribed drug might not work as expected when used with other medications that potentially affect its pharmacotherapy. This is termed as a drug-drug interaction. A specific drug used to treat a disease could have an undesirable effect on another disease or a symptom. This is termed as drug-disease interaction. Like, NSAIDs, which are commonly used as pain killers, could increase blood pressure and cause nephropathy and therefore, it should not be used by patients with high blood pressure or with various kidney disorders [7] (Table 1). 
Citation: Hassan M, Akbar FM, Rafia Begum, et al. Prevalence of Drug-Drug Interactions in Intensive Care Unit of a Multispecialty Hospital at Hyderabad, South India. Int J Gen Med Surg 2019; 3: 125. doi: $\underline{10.31531 / 2581-8287.1000125}$

Table 1: List of frequently interacting drug combinations ranked according to frequency and severity.

\begin{tabular}{|c|c|c|c|}
\hline Rank & Drug Combination & Severity & Frequency \\
\hline 1 & Aspirin + Enoxaparin & Major & 5 \\
\hline 2 & Furosemide+ Ramipril & Moderate & 5 \\
\hline 3 & Atorvastatin + Ranolazine & Moderate & 4 \\
\hline 4 & Heparin + Nitroglycerin & Moderate & 4 \\
\hline 5 & Furosemide+ Cefoperazone & Moderate & 4 \\
\hline 6 & Piperacillin + Vancomycin & Moderate & 4 \\
\hline 7 & Ceftriaxone + Heparin & Minor & 5 \\
\hline 8 & Ondansetron + Metronidazole & Minor & 5 \\
\hline
\end{tabular}

\section{Materials and Methods}

This is a prospective observational study carried out in ICU of a multi-specialty hospital, (300 bedded hospital) that receives patients with chronic degenerative diseases that frequently use a wide variety of medicines for a long period of time.

\section{Inclusion criteria}

Patient of age group between 18-80 years of both the genders admitted to ICU for more than 24 hours and prescribed at least more than 2 drugs are included in the study.

\section{Exclusion criteria}

Patients who are treated in outpatient department, those who stayed for less than 24 hours in the hospital, pregnant and lactating women, and patients below the age of 18 years were excluded.

All the relevant and necessary data of the patients including the demographic data, laboratory parameters and drug therapy details were collected from the patient case notes. The demographic details consist of age, gender, reason for admission, past medical history, medication history, co-morbidities and any history of allergic reactions. The recording of laboratory parameters includes hematology, biochemistry and any other tests that were carried out during their hospital stay. The drug therapy details such as dose, duration, frequency, route, time of administration and concomitant drug were also noted. All the collected data was documented in a suitably designed data collection form which was designed as per the need of the study. Total no. of drugs was analyzed and the presence of polypharmacy. Polypharmacy is defined as the use of more than five drugs. As well as most widely used subgroups according to ATC classification were analyzed. In order to identify substances and dosages from their trade names, drugs.com, Medscape was used. The active principle present in each specialty is listed and classified according to the ATC system (WHO). The search for Drug-drug interactions and it nature within the prescription was performed using the software Clinirex, and online sources such as Medscape Drug Interaction Checker, and Drugs.com. A tertiary source of reference Stockley's Drug Interactions was referred. Supplements, electrolytic components, insulin and vitamin supplements were excluded from the study. The DDIs were identified at the end of the follow up, researchers were not aware of any potential drug interactions during the process of data collection. This study did not foresee methods of investigating the actual incidence of interactions. PDDIs were classified as: major (this type of interaction may be lifethreatening); moderate (the interaction may result in deterioration of the patient's condition); or minor (the interaction have limited or no clinical effects). Also, it was possible for correlation of presence of pDDIs with factors such as the no. of drugs prescribed, age, and gender. Mechanism of drug-drug interactions may be pharmacokinetic and pharmacodynamics in nature or of unknown mechanism. Polypharmacy was classified as: minor polypharmacy (2-4 drugs), major polypharmacy (greater than or equal to 5 drugs in each prescription) and hyper polypharmacy (greater than or equal to 10 drugs in each prescription). After determination of polypharmacy, DDIs and their mechanisms, data was analyzed by the researchers in accordance to the objectives of the study.

\section{Result}

A total of 151 prescription assessed out of which 69 were female and 82 were male. There was a slight majority of male patients although; there was no statistically substantial association between drug interactions and the frequency of male patients. The most common age group that had been admitted to the 
Citation: Hassan M, Akbar FM, Rafia Begum, et al. Prevalence of Drug-Drug Interactions in Intensive Care Unit of a Multispecialty Hospital at Hyderabad, South India. Int J Gen Med Surg 2019; 3: 125. doi: $\underline{10.31531 / 2581-8287.1000125}$

ICU is 41-60 years, the average age was 54.6 and association was found between the DI and increased age. A significant link was found between the number of medications prescribed and the degree of severity between the observed drug interactions. From 151 patients, out of which 108 patients drug prescriptions contained potential drug-drug interactions. From a total of 276 drug interactions found in 108 prescriptions, 46 drug-drug interactions were of major severity, 184 drug-drug interactions of moderate severity and 46 drug-drug interactions of minor severity. It was observed that $3.31 \%(\mathrm{n}=5)$ patients with moderate polypharmacy, $41 \% \quad(n=62)$ patients with major polypharmacy and $55.6 \%(\mathrm{n}=84)$ patients with hyper-polypharmacy. From a total of 276 drug interactions found, 46 drug interactions were of major severity, 184 drug interactions of moderate severity and 46 drug interactions of minor severity. Mechanism of DDI was identified of which 85 (30.7\%) DDI showed pharmacokinetic mechanism, 135 (48.9\%) DDI showed pharmacodynamic mechanism and 56(20.6\%) DDI showed unknown mechanism. Table 2 provides a detailed description of the most used medication according to the anatomical (level 1) and therapeutically (level 2) classification of the ATC.

Table 2: Description of medicines used by the study population, according to ATC classification.

\begin{tabular}{|c|c|}
\hline \multicolumn{2}{|l|}{ Alimentary Tract and Metabolism } \\
\hline Antacids/Antiulcer/Antiflatulents & $202(15.34 \%)$ \\
\hline Antispasmodic, anticholinergic \& propulsive agents & $35(2.65 \%$ \\
\hline Drugs used in Diabetes & $40(3 \%)$ \\
\hline Vitamins & $168(12.76 \%)$ \\
\hline \multicolumn{2}{|l|}{ Nervous System } \\
\hline Analgesics & $79(6 \%)$ \\
\hline Antiepileptics & $36(2.73 \%)$ \\
\hline \multicolumn{2}{|l|}{ Cardiovascular System } \\
\hline Cardiac drugs & $147(11.17 \%)$ \\
\hline Diuretics & $48(3.6 \%)$ \\
\hline Inhibitors of Renin-Angiotensin System & $19(1.4 \%)$ \\
\hline Hypolipidemic agents & $65(4.9 \%)$ \\
\hline \multicolumn{2}{|l|}{ Respiratory System } \\
\hline Nasal preparation & $26(1.97 \%)$ \\
\hline Anti-asthmatics & $34(2.5 \%)$ \\
\hline \multicolumn{2}{|l|}{ General Anti-infectives for systemic use } \\
\hline Antibacterial for systemic use & $214(16.2 \%)$ \\
\hline Antimycotics for systemic use & $17(1.2 \%)$ \\
\hline Antiviral & $12(0.9 \%)$ \\
\hline \multicolumn{2}{|l|}{ Blood \& Blood forming organs } \\
\hline Antithrombotic agents & $145(11 \%)$ \\
\hline Systemic hormone prep., excluding Sex hormones \& Insulin & $29(2.2 \%)$ \\
\hline $\begin{array}{l}\text { Among the most prescribed therapeutic classes, } \\
\text { medications that act in the alimentary tract and } \\
\text { metabolism are highlighted }(33.75 \%) \text {; nervous system } \\
(8.73 \%) \text {; cardiovascular system }(21.07 \%) \text {; respiratory } \\
\text { system }(4.47 \%) \text {; general anti-infectives for systemic } \\
\text { use }(18.3 \%) \text {; blood and blood forming organs }(11 \%) \text {; } \\
\text { and systemic hormonal preparations excluding sex } \\
\text { hormones and insulin (2.2\%). } \\
\text { Polypharmacy } v \text { s. DDI category }\end{array}$ & $\begin{array}{l}\text { On comparing DDI based on age group it was found } \\
\text { that patient in the age group of } 41-60 \text { years constituted } \\
\text { the highest number of patients that is } 49 \% \text { of the total } \\
\text { patients followed by } 32 \% \text { in age group between } 61- \\
80 y e a r s \text { and } 17.5 \% \text { in age group between } 21-40 \text { years. } \\
\text { Among the } 276 \text { drug-drug interactions observed in } 108 \\
\text { patients, } 11(3.98 \%) \text { DDI was observed in patients with } \\
\text { moderate polypharmacy ( }=3 \text { and } 79(28.6 \%) \text { DDI } \\
\text { was observed in patients with major polypharmacy } \\
(n=38) \text { and } 186(67.3 \%) \text { DDI was observed in patients }\end{array}$ \\
\hline
\end{tabular}


Citation: Hassan M, Akbar FM, Rafia Begum, et al. Prevalence of Drug-Drug Interactions in Intensive Care Unit of a Multispecialty Hospital at Hyderabad, South India. Int J Gen Med Surg 2019; 3: 125. doi: $\underline{10.31531 / 2581-8287.1000125}$

with hyper-polypharmacy $(n=67))$. The DDI was categorized into 3 types based on significance of the reaction which include major, moderate and minor. The prevalence of drug-drug interaction were seen more in age group of 41-60 [n=125 (45.2\%) out of 276] followed by 61-80 years of age group [n=103(37.3\%) out of 276] and 21-40 years of age group [ $\mathrm{n}=48$ (17.39\%) out of 276] (Table 3).

Table 3: DDI based on Polypharmacy vs. age group.

\begin{tabular}{|c|c|c|c|c|c|c|}
\hline \multirow[b]{2}{*}{ Age } & \multirow[b]{2}{*}{ Polypharmacy } & \multirow[b]{2}{*}{ Frequency } & \multirow[b]{2}{*}{ DDI's } & \multicolumn{3}{|c|}{ DDI Categories } \\
\hline & & & & Major & Moderate & Minor \\
\hline \multirow{3}{*}{$21-40$} & $\begin{array}{l}\text { Moderate } \\
\text { Polypharmacy }\end{array}$ & 0 & 0 & 0 & 0 & 0 \\
\hline & $\begin{array}{l}\text { Major } \\
\text { Polypharmacy }\end{array}$ & 8 & 18 & 4 & 14 & 0 \\
\hline & $\begin{array}{l}\text { Hyper } \\
\text { Polypharmacy }\end{array}$ & 11 & 30 & 11 & 12 & 7 \\
\hline \multirow{3}{*}{$41-60$} & $\begin{array}{l}\text { Moderate } \\
\text { Polypharmacy }\end{array}$ & 2 & 8 & 0 & 8 & 0 \\
\hline & $\begin{array}{l}\text { Major } \\
\text { Polypharmacy }\end{array}$ & 19 & 32 & 4 & 23 & 5 \\
\hline & $\begin{array}{l}\text { Hyper } \\
\text { Polypharmacy }\end{array}$ & 33 & 85 & 11 & 55 & 19 \\
\hline \multirow{3}{*}{$61-80$} & Moderate Polypharmacy & 1 & 3 & 0 & 3 & 0 \\
\hline & Major Polypharmacy & 11 & 29 & 2 & 22 & 5 \\
\hline & Hyper Polypharmacy & 23 & 71 & 14 & 47 & 10 \\
\hline Total & & 108 Patients & 276 & 46 & 184 & 46 \\
\hline
\end{tabular}

In our study out of a total of 151 cases collected, $71.5 \%$ of cases had the potency of drug-drug interactions. Similarly, other studies reviewed reported a $70 \%$ prevalence of potential drug interactions in the ICU patients $[8,9]$. However, a much higher frequency of drug interactions (91.43\%) [10]. Another study showed a lower frequency of drug interactions $(67.1 \%)$ [11]. Differences in the level of sensitivity and specificity of the methodologies used in identifying the potential drug interactions may explain the difference between the studies.

This study showed a slight majority of male patients. A total of 151 prescriptions were assessed out of which 69 were female and 82 were male. Although, literature review showed a slight predominance of female patients [12]. Although some claim that female receives more medicines and are more likely to have drug interactions [13], previous studies showed that men are at higher risk of drug interaction in critical care unit compared to women and the possibility of interaction have inverse relationship with patients age $[13,14]$. In this study, we found no link between the frequency of male patients and drug-drug interactions. This can be justified by higher percentage of men
The average age of subjects in this study is 54 years, an association between elderly people and the presence of drug interactions was found. In other studies, age is a significant risk factor for drug-drug interactions, since geriatrics have associated health conditions that favor a longer stay at the hospital and increased use of drugs. This leads to prescribing of even more complex therapeutic combinations further leading to drug-drug interactions. Generally, patients in critical care are often aged and have physiological changes, adding up to unfavorable conditions for drug metabolism such as shock, renal failure, and liver disease. It can be inferred that relevance of potential interactions, even if not significant it is applicable for prevention of undesirable adverse effects $[11,13]$.

Number of drugs prescribed is one of the determinants of drug interactions. The average number of drugs that were given to patients in this study is 11 drugs. In previous studies the average number of drugs given to patients was 7. A study found that the average number of drugs administered to patients was 13 drugs. It was apparent that patients from the group of significant PDDIs were prescribed a higher number of drugs 
during their stay, a higher number of drugs per day and a longer length of stay in ICU, possible due to increased load of drug exposure and different drug combinations.

Number of drugs prescribed is one of the determinants of drug interactions. The average number of drugs that were given to patients in this study is 11 drugs. In previous studies the average number of drugs given to patients was 7.

In this study it was found that most of the potential drug-drug interactions were of moderate severity (65.9\%). Various studies also confirm that most drug interactions identified were of moderate severity [9$11]$.

Most prescribed drugs were alimentary and metabolism agents, followed by cardiovascular and general anti-infectives. The data for alimentary tract and metabolism are comparable to the study conducted in ICU in Brazil [12]. The use of medications that act in alimentary tract and metabolism has been a practice in ulcer prophylaxis in critically ill patients, since many diseases that require hospitalization are directly associated with gastric mucosal lesions $[14,15]$.

\section{Conclusion}

This is a prospective observational study where patients aged 21-80 years are included in the study. All the relevant and necessary details of the patients including the demographic data, laboratory parameters and drug therapy details were collected from the patient case notes. A total of 151 prescription assessed out of which 69 were female and 82 were male. There was a slight predominance of male patients although, there was no statistically relevant association between drug interactions and the frequency of male patients. In the study group the average age was 54.6 and association was found between the DI and increased age. More substantial association was found between the number of drugs prescribed and the degree of severity between the observed drug interactions. There were around 1,709 drugs prescribed and average drugs per prescription was 11.2 among 134 patients it was observed that $3.31 \%(n=5)$ patients with $1-4$ drugs per prescription; $24.5 \%(\mathrm{n}=37)$ patients with 5-8 drugs per prescription; $43 \%(\mathrm{n}=65)$ patients with $9-13$ drugs per prescription; $18.5 \%(\mathrm{n}=28)$ patients with 14-16 drugs per prescription; $7.9 \%(\mathrm{n}=12)$ patients with $17-20$ drugs per prescription; and $2.64 \%(\mathrm{n}=4)$ patients with 21-24 drugs per prescription. It was observed that $3.31 \%(\mathrm{n}=5)$ patients with moderate polypharmacy,
$41 \%(\mathrm{n}=62)$ patients with major polypharmacy and $55.6 \%(\mathrm{n}=84)$ patients with hyper-polypharmacy. From a total of 276 drug interactions found, 46 drug interactions were of major severity, 184 drug interactions of moderate severity and 46 drug interactions of minor severity. Mechanism of DDI was identified of which $85(30.7 \%)$ DDI showed pharmacokinetic mechanism, 135(48.9\%) DDI showed pharmacodynamic mechanism and 57(20.6\%) DDI showed unknown mechanism. Table 2 provides a detailed description of the most used medication according to the anatomical (level 1) and therapeutical (level 2) classification of the ATC. Among the most prescribed therapeutic classes, medications that act in the alimentary tract and metabolism are highlighted (33.75\%); nervous system (8.73\%); cardiovascular system (21.07\%); respiratory system $(4.47 \%)$; general anti-infectives for systemic use (18.3\%); blood and blood forming organs (11\%); and systemic hormonal preparations excluding sex hormones and insulin $(2.2 \%)$.

It can be concluded that prevalence of pDDIs is high in intensive care units and is largely influenced by factors such as the number of drugs prescribed to the patients, their chronic conditions; complexity of pharmacotherapies administered and advancing age. Healthcare professionals who provide care, should be mindful about drug-drug interactions to identify and prevent possible drug events. Also, the pharmacist's involvement might have allowed greater familiarity of physicians regarding clinically relevant drug-drug interactions, optimizing the quality of the prescriptions, especially in critical care units. Therefore, the outcome of clinical pharmacist's applications and intervenes may promote well-being, preventing and monitoring adverse events, intervening and contributing to pharmacotherapy effectiveness and prioritizing patient safety.

\section{References}

1. H Rafiei, Abdar ME, Amiri M, et.al, The study of harmful and beneficial drug interactions in intensive care. J Intensive Care Society 2013; 14 : 155-158.

2. https://www.wisegeek.com/what-is-an-icu.htm

3. Lal HM, Lal U. Drug interactions- mechanisms and clinical implications. Medicine update Chapter 89 2008; 18: 674-690.

4. Mohamed SMAES, Gad ZM, El-Nimr NA, et al. Prevalence and pattern of potential drug-drug interactions in the critical care units of a tertiary 
hospital in Alexandria, Egypt. Adv Pharmaco Drug Safety 2013; 2: 144.

5. Abideen S. Assessment of the prevalence of drugdrug interactions in the medical intensive care unit of a tertiary care teaching hospital in India. Asian J Pharm Clin Res 2015; 8: 125-130.

6. Pichala PT, Kumar BN, Zachariah S, et al. An interventional study on intensive care unit drug therapy assessment in a rural district hospital in India. J Basic Clin Pharma 2013; 4: 64-7.

7. https://www.serviciofarmaciamanchacentro.es/ima ges/stories/recursos/recursos/docinteres/conciliacio $\mathrm{n} /$ stockleys $\% 20 \mathrm{drug} \% 20$ interactions $\% 208$ th $\% 20 \mathrm{e}$ dition1.pdf

8. Reis AMM, Cassiani SHDB. Prevalence of potential drug interactions in patients in an intensive care unit of a university hospital in Brazil. Clinics 2011; 66: 9-15.

9. Hamidy MY, Fauzia D. Significant drug interactions among intensive care unit patients, Asian J Pharm Clin Res 2017; 10: 35-38.

10. Valizade H, Amin M, Hamdolah S, et al. Drugdrug interactions prevalence in intensive care unit patients of a university hospital in Iran, Bull Env Pharmacol Life Sci 2014; 3: 87-91.

11. Hammes JA, Pfuetzenreiter F, Silveira FD, et al. Potential drug interactions prevalence in intensive care units. Rev Bras Ter Intensiva 2008; 20: 349354.

12. Andrade TNG, Silvestre CC, Cunha LC, et al. Pharmaceutical intervention assessment in the identification and management of drug interactions in an intensive care unit. J App Pharm Sci 2015; 5: 13-18.

13. Lima RE, Cassiani SHB. Potential drug interactions in intensive care patients at a teaching hospital. Rev Latino Am Enfermagem 2009; 17: 222-227.

14. Araujo TE, Vieira SMG, Carvalho PRA. Stress ulcer prophylaxis in pediatric intensive care units. J pediatr 2010; 86: 525-530.

15. Pompilio CE, Cerconello I. Prophylaxis of ulcers associated with stress. Arq Brascir Dig 2010; 62:294-298.

This manuscript was peer-reviewed

Mode of Review: Single-blinded

Academic Editor: Srinivas $P$

Copyright: (02019 Hassan M, et al. This article is distributed under the terms of the Creative Commons Attribution 4.0 International License (http://creativecommons.org/licenses/by/4.0/), which permits unrestricted use, distribution, and reproduction in any medium, provided you give appropriate credit to the original author(s) and the source, provide a link to the Creative Commons license, and indicate if changes were made. 